\title{
EXPERIMENTAL STUDY INVESTIGATING VARIOUS SHOREFACE NOURISHMENT DESIGNS
}

\author{
D.J.R. Walstra ${ }^{1,2}$, C.W. Hoyng ${ }^{3}$, P.K. Tonnon ${ }^{1}$, L.C. Van Rijn ${ }^{1,4}$
}

\begin{abstract}
This experimental study focuses on the morphological development of a near-equilibrium profile on which to types of shoreface nourishments are placed. As previous studies have indicated that the efficiency of nourishments is mainly influenced by water depth in which they are constructed, two cross-shore locations are considered for an accretive and an erosive wave condition. A nourishment relatively high in the profile covering the trough and a nourishment relatively low in the profile just seawards of the breaker bar were investigated. Detailed measurements of wave height, velocities and sediment transport are combined with the observed morphological development to identify the processes that dominate the morphological development. The results confirm that the cross-shore location of nourishment has a major influence. The nourishment in relative deep water reduces the erosion of the upper part of the profile by about $20 \%$ for the accretive condition and $40 \%$ for the erosive condition. The nourishment higher in the profile results in a reduction of the erosion volume of $60 \%$ for both wave conditions.
\end{abstract}

Keywords: shoreface nourishment, physical experiment, process measurements

\section{INTRODUCTION}

The Dutch government policy of "Dynamic Preservation" was implemented in 1990 with the strategic objective to combine high sustainable safety levels with a sustainable preservation of values and functions of the coast. The policy involved the initiation of a nourishment program with the operational objective to main the coastline seaward from its 1990 position (see e.g. Van Koningsveld and Lescinski, 2006). The majority of the nourishments are carried out as shoreface nourishments. Shoreface nourishments typically have a total volume of 1-2 million $\mathrm{m}^{3}$ and an alongshore length of several km's (van Duin et al., 2004). Only general guidelines exist which state that the nourished volume per meter coast should be similar to the volume of the main breaker bar and that the sand should be placed in the active zone above the depth of closure. Although shoreface nourishments have proven to be an effective measure to mitigate erosion (e.g. Hamm et al., 2002) the relative importance of forcing processes is still unknown. To study the crossshore morphodynamic impact of shoreface nourishment and the associated hydrodynamics and sediment transports a physical experiment was carried out in Deltares' Scheldt flume. The experiments focus on bed profile development and process-based measurements. This paper aims at establishing and quantifying the dominant physical processes that are affected by the presence of a shoreface nourishment. Test results will enhance knowledge of efficiency of nourishment designs by linking process-based measurements with bed profile measurements.

The construction water depth of a shoreface nourishment is considered to be the most important design parameter (e.g. Walstra et al., 2004). The effect of a shoreface nourishment on the bed profile development largely depends on its position in the profile. Therefore, two nourishment designs are investigated: a design located seawards of the breaker bar and a design higher in the coastal profile. The high nourishment design is located on top of the original breaker bar and covers the trough. The nourishments have an identical volume $\left(400 \mathrm{~m}^{3} / \mathrm{m}\right.$ in proto type scale). In addition a natural profile was also considered to act as a reference.

${ }^{1}$ Deltares - Delft Hydraulics, PO Box 177, 2600 MH Delft, The Netherlands. DirkJan.Walstra@Deltares.nl, Leo.vanRijn@ Deltares.nl, PieterKoen.Tonnon@ Deltares.nl, Voice: +31 88 3358287, Fax: + 31152858710.

2 Delft University of Technology, Faculty of Civil engineering and Geosciences, Section Hydraulic Engineering, PO Box 5048, 2600 GA, Delft, The Netherlands.

${ }^{3}$ Royal Haskoning, Advisory Group Coastal \& Rivers, PO Box 8520, 3009 AM Rotterdam, The Netherlands, C.Hoyng@RoyalHaskoning.com.

${ }^{4}$ University of Utrecht, Coastal Research Group, Department of Physical Geography, P.O. Box 80.115, 3508 TC Utrecht, Netherlands. 


\section{EXPERIMENTAL SETUP}

\section{Wave Flume}

The experiments have been conducted in Deltares' Scheldt flume. The flume, consisting of an iron bottom and glass walls, has an overall length of $56 \mathrm{~m}$, a width of $1 \mathrm{~m}$ and a depth of $1.2 \mathrm{~m}$. The wave generator located at the beginning of the flume is equipped with an online active reflection compensation in which reflected waves are compensated for by separating them from outgoing waves. In addition, the wave board is equipped with second order wave steering to compensate for spurious waves.

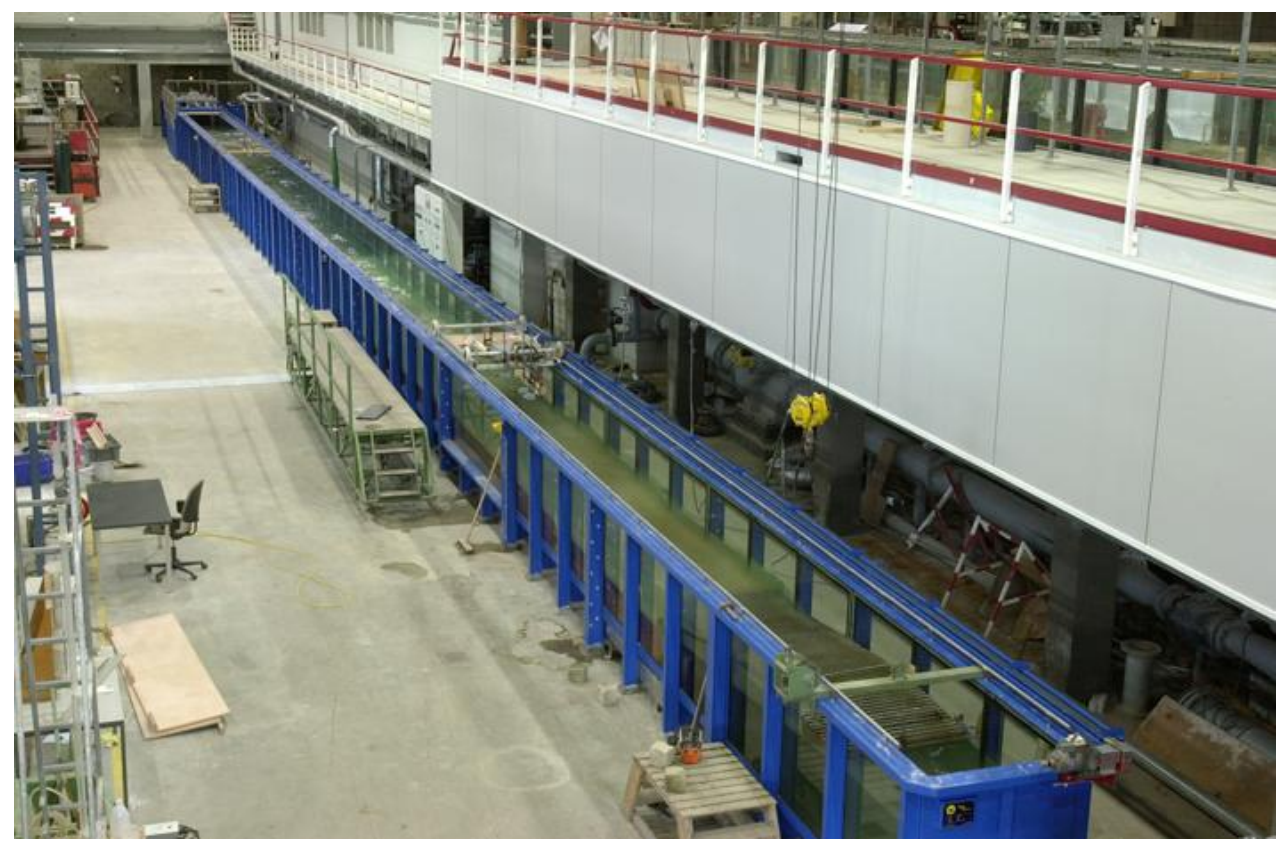

Figure 1. Scheldt flume at Deltares.

\section{Measurements}

During the experiments, bed profiles, water level variations, flow velocities, sediment concentrations and sediment transport have been measured. The flume is equipped with a rail-guided carriage, which allows automatic profile surveying. Three probes at a mutual distance of $25 \mathrm{~cm}$ move up, forward and down again (Figure 2). At fixed time intervals the bed profile is measured by the bed profiler. The results of the three parallel measurements give the average bed profile. Cross-shore non-uniformity of the bed profile has been checked and can be neglected.

Along the flume, several wave gauges record the free surface elevations with resistance type twin-wires. The output signal range from -10 to $10 \mathrm{~V}$ corresponds to a water elevation measuring range from $-0.25 \mathrm{~m}$ to $0.25 \mathrm{~m}$.

During each test, five process-based measurements were carried out. These process-based measurements focused on measurements of wave-induced velocities and sediment concentrations. The flow velocities were measured with an ADV and EMV. The suspended sediment concentrations were measured using an acoustic sediment transport monitor (ASTM) and a Transverse Suction System to simultaneously measure time-averaged suspended-sediment concentrations at ten different heights (TSS, Bosman et al., 1987). A reference rod was used to determine to position the instruments consistently $1.5 \mathrm{~cm}$ above the bed. This equipment was all attached to a second rail-guided carriage (see Figure 2). The ADV, EMV and ASTM measured for 5 minutes at the exact vertical location of the 10 TSS suction tubes.

The sediment used for the tests in the Scheldt flume is Sibelco AF100 sediment. D50 is slightly larger than $130 \mu \mathrm{m}$ (Figure 3). 
A Visual Accumulation Tube (VAT) was used to determine the suspended sediment grain size and fall velocity from the sand collected by the TSS. The VAT consists of a settling tube with a length of about 2 $\mathrm{m}$ and a diameter of approximately $3 \mathrm{~cm}$. The sample is released on top of the tube by means of a simple clamp device. Under the settling tube a small tube is suspended in which the deposit height can be determined as a function of time. Based on this information, the fall velocity distribution can be determined. In the left plot of Figure 4 sieved sand is compared with VAT estimates. It can be seen that for smaller sediment the VAT under-estimates the grain size slightly. This due to the fact that for small grains cohesive forces and trapping becomes relative more important. Therefore separate conversions were determined which are shown in the middle and right plots of Figure 4:

$$
\begin{aligned}
& D_{s}=1.5 D_{\text {vat }}-49 \quad \text { for } D_{01} \text { to } D_{05} \\
& D_{s}=0.91 D_{\text {vat }}+20 \quad \text { for } D_{10} \text { to } D_{90}
\end{aligned}
$$
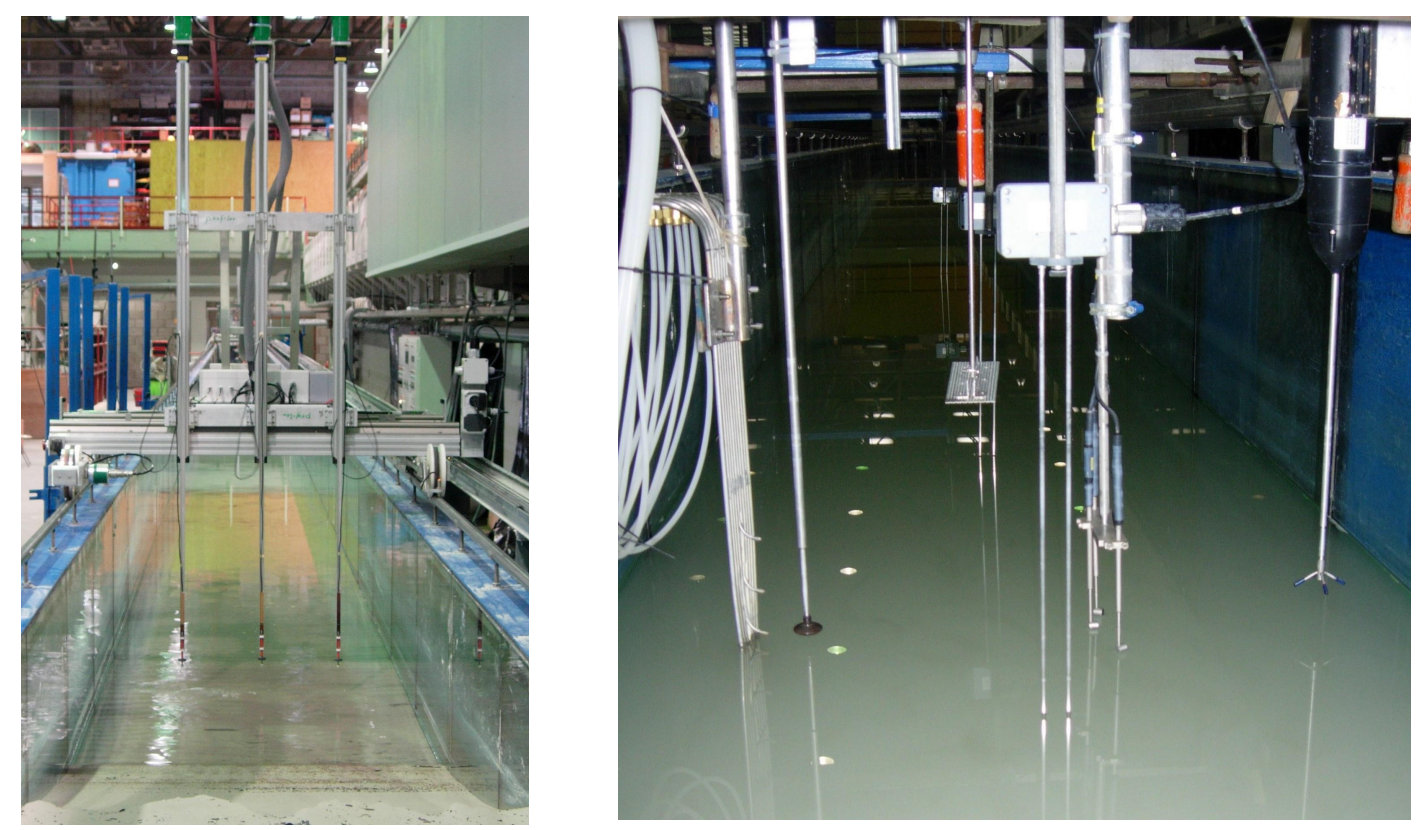

Figure 2. Left: bed profiler with three probes. Right: carriage with (from left to right): TSS, EMS, reference rod, WHM, ASTM and ADV.

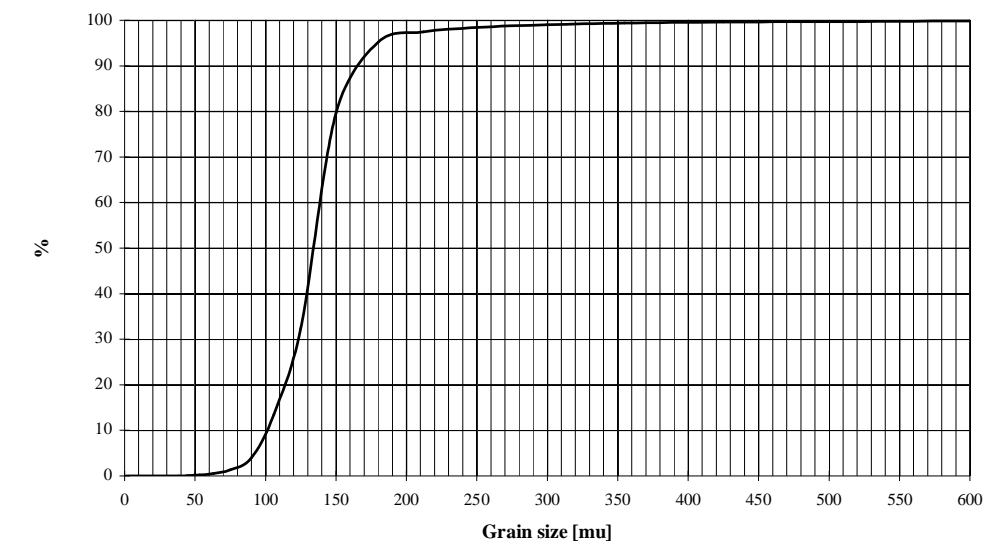

Figure 3. Grain size distribution of the sediment in the Scheldt flume. 

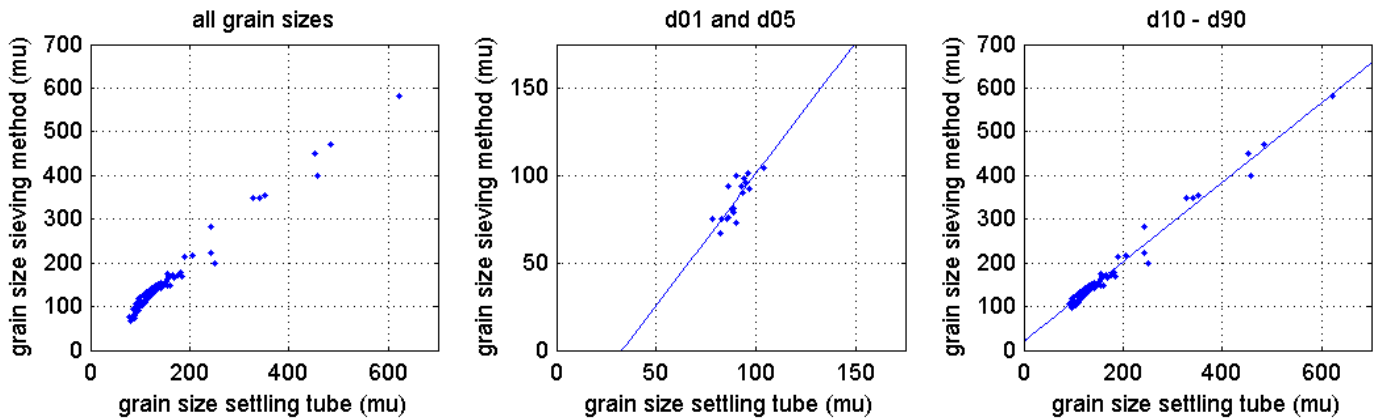

Figure 4. Calibration of Visual Accumulation Tube (VAT) with sieved sediments.

\section{Nourishment Designs}

The experiments were designed to investigate two different nourishment designs with identical volumes: a nourishment relatively high in the profile covering the trough and a nourishment relatively low in the profile just seawards of the breaker bar (see Figure 5). In addition a natural profile was also considered to act as a reference. All profiles were subjected to an accretive and an erosive wave condition (Table 1).

\begin{tabular}{|l|l|l|l|}
\hline \multicolumn{4}{|c|}{ Table 1: Overview of morphodynamic experiments in Scheldt flume. } \\
\hline Experiment & Wave condition $\left(\mathrm{H}_{\mathrm{s}} / \mathrm{T}_{\mathrm{p}}\right)$ & Design & Duration (hrs) \\
\hline T02 & $0.10 \mathrm{~m} / 3.0 \mathrm{~s}$ & Reference & 24 \\
\hline T03 & $0.17 \mathrm{~m} / 2.3 \mathrm{~s}$ & Reference & 16 \\
\hline T04 & $0.10 \mathrm{~m} / 3.0 \mathrm{~s}$ & Low Nourishment & 24 \\
\hline T05 & $0.17 \mathrm{~m} / 2.3 \mathrm{~s}$ & Low Nourishment & 16 \\
\hline T06 & $0.10 \mathrm{~m} / 3.0 \mathrm{~s}$ & High Nourishment & 24 \\
\hline T07 & $0.17 \mathrm{~m} / 2.3 \mathrm{~s}$ & High Nourishment & 16 \\
\hline
\end{tabular}

Besides regular profile measurements $(0,1,3,8,16,24$ hours) detailed velocity and sediment concentration measurements were carried over the water column out at five horizontal locations (indicated in Figure 5).

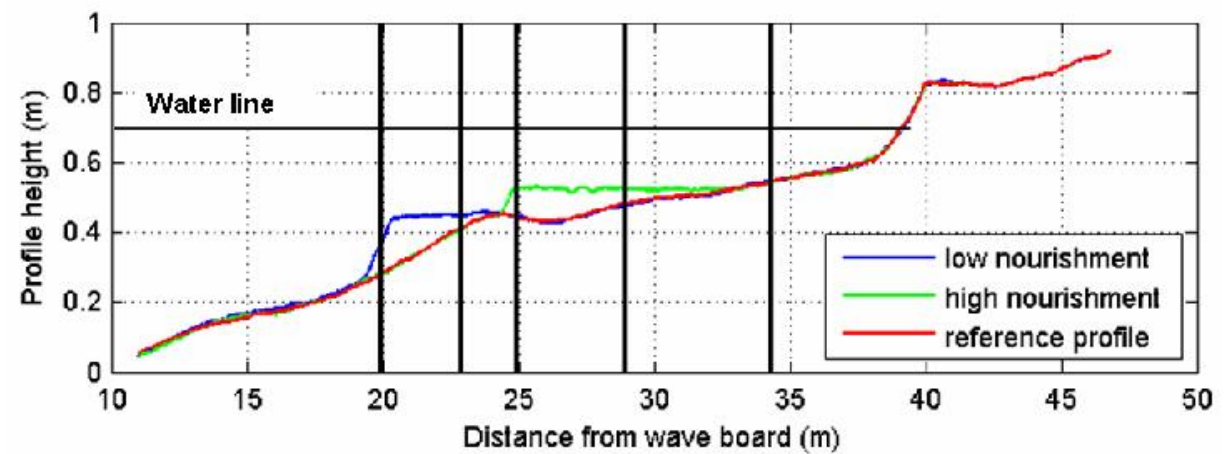

Figure 5. Initial profiles for the reference case and both nourishment cases, vertical black lines indicate positions of detailed hydrodynamic and sediment concentration measurements. 


\section{OBSERVED MORPHOLOGICAL DEVELOPMENT}

In Figure 6 to Figure 11, the beach profile development of the reference tests and the tests with the two nourishment designs are shown. It is clear that for the both accretive and erosive wave conditions the upper part of the profile ( $>32 \mathrm{~m}$ ) is eroding. However, for the reference case (Figure 6 and Figure 7), the bar at $\mathrm{x}=24 \mathrm{~m}$ is showing an opposite migration response to both wave conditions. The erosive wave condition results in an offshore migrating breaker bar, whereas the accretive wave condition results in a landward migration of the breaker bar.

The observed nourished profile developments under accretive waves (Figure 8 and Figure 10) show that the low nourishment has a similar response as the reference profile, whereas the high nourishment is more or less stable. The height of the breaker bar of the reference tests and of the test with the low nourishment increases. The nourished sand is transported landward and a bar is developing with a crest at about $0.5 \mathrm{~m}$. However, the upper part of the profile is still eroding for both nourishment designs.

For the erosive wave condition the lower nourishment reacts in a similar way as for the accretive wave condition: a bar is developing at the nourishment with a crest height of about $0.5 \mathrm{~m}$. The high nourishment now shows a clear offshore migration with a bar emerging with a similar crest height of 0.5 $\mathrm{m}$.

By subtracting the reference profiles from the nourished profiles the impact of the nourishments is visualized. As the profiles were measured at the same times, the relative impact can be assessed as the profiles are changing during the experiment. In Figure 12 the relative changes for the low nourishment design are shown for the accretive condition (top plot) and erosive condition (bottom plot). For the accretive wave condition a relative large part of the sediment is moved onshore. For the erosive wave condition more of the nourished sediment is stable with some diffusion at both distal ends. The upper part of the profile shows a relative increase which, as both the nourished and reference profile are eroding in this area, should be interpreted as an absolute decrease of the erosion due to the nourishment. The same relative changes are evaluated for the high nourishment design in Figure 13. Compared to the low nourishment, the high nourishment shows more diffusion of nourished sand across the profile. The high nourishment design results in a decreased erosion of the upper part of the profile for both the accretive and erosive wave conditions.

The erosion volumes are determined for the upper part of the profile $(32 \mathrm{~m}<\mathrm{x}<47.7 \mathrm{~m})$ to quantify the effect of the two nourishment designs. Figure 14 (Figure 15) shows the erosion volumes of the accretive (erosive) tests for the reference and nourished profiles. It can clearly be observed that both designs have a positive influence on the upper profile development. The reference profile is subject to the largest erosion, $0.3 \mathrm{~m}^{3} / \mathrm{m}$ for the accretive test and approximately $0.2 \mathrm{~m}^{3} / \mathrm{m}$ for the erosive test. The larger erosion of the upper part of the profile for the accretive waves is most-likely caused by the fact that the initial profile in the present experiment was obtained by subjecting a profile to 8 hours with the erosive wave condition (the starting profile was the measured final profile from the experiments by Koomans and Bosboom, 2000). Therefore the upper part initial profile is probably more in equilibrium with the erosive wave condition, resulting in less erosion for this wave condition.

The low nourishment reduces the erosion to $0.25 \mathrm{~m}^{3} / \mathrm{m}$ for the accretive test and $0.12 \mathrm{~m}^{3} / \mathrm{m}$ for the erosive test. The high nourishment results in the largest reduction for both wave conditions: $0.12 \mathrm{~m}^{3} / \mathrm{m}$ for the accretive test and $0.08 \mathrm{~m}^{3} / \mathrm{m}$ for the erosive test.

To obtain better insight into the effects of the nourishments on the bed profile development, the relative increase of sand volume in the coastal zone is shown in the right plots of Figure 14 and Figure 15. The low nourishment results in a relative increase of sand volume, $20 \%$ for the accretive condition and $40 \%$ for the erosive condition. The high nourishment has the largest relative increase of sand volume: $60 \%$ for both wave conditions. 


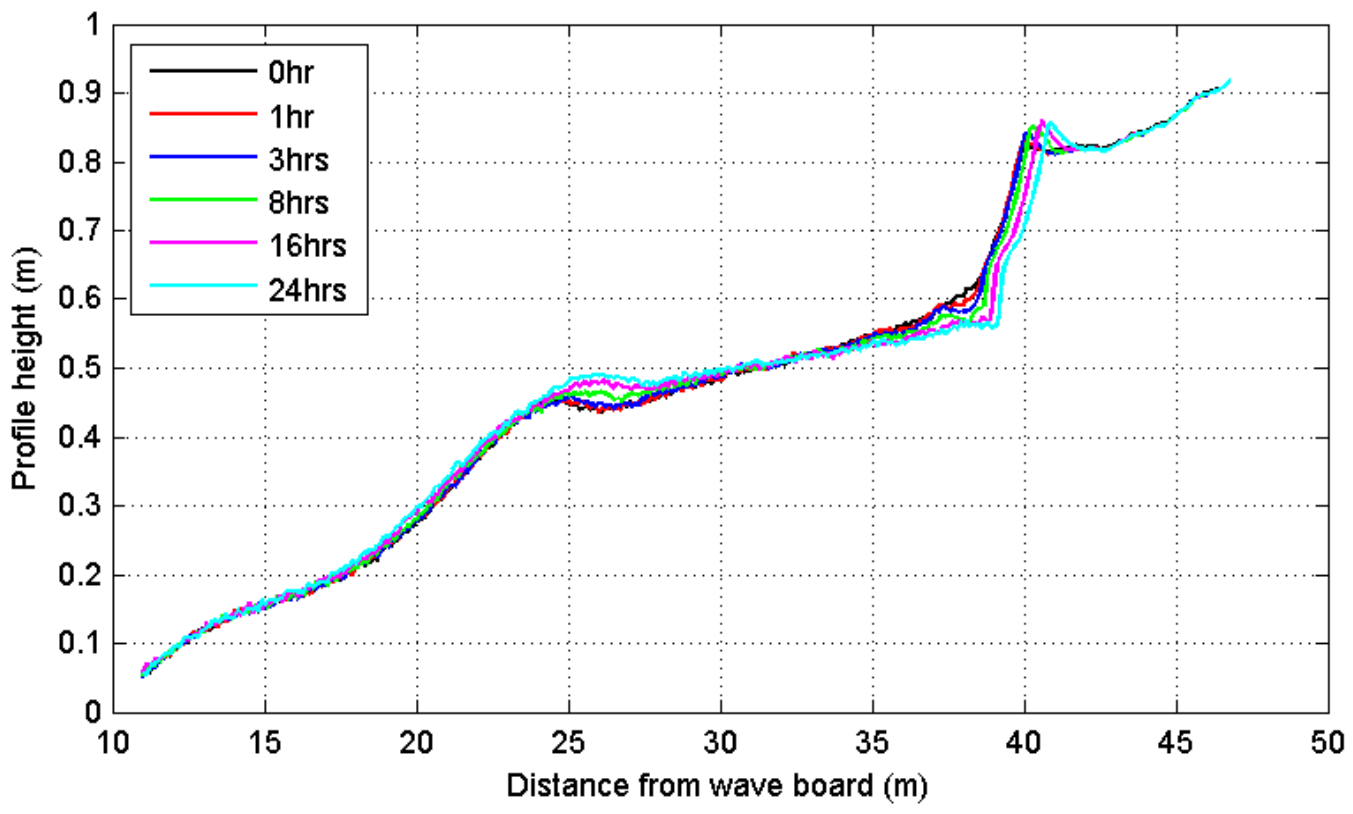

Figure 6. Observed profile development for the reference profile under accretive wave conditions.

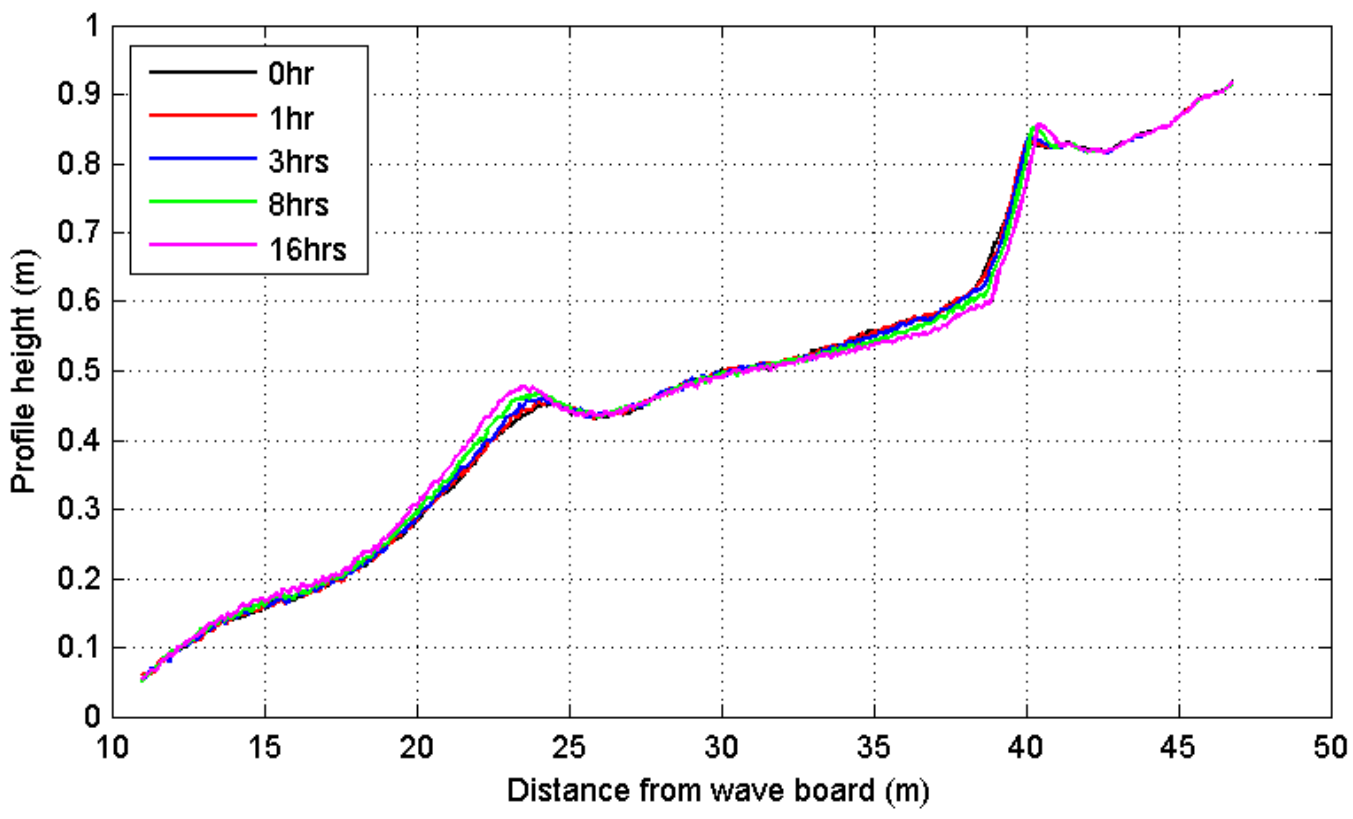

Figure 7. Observed profile development for the reference profile under erosive wave conditions. 


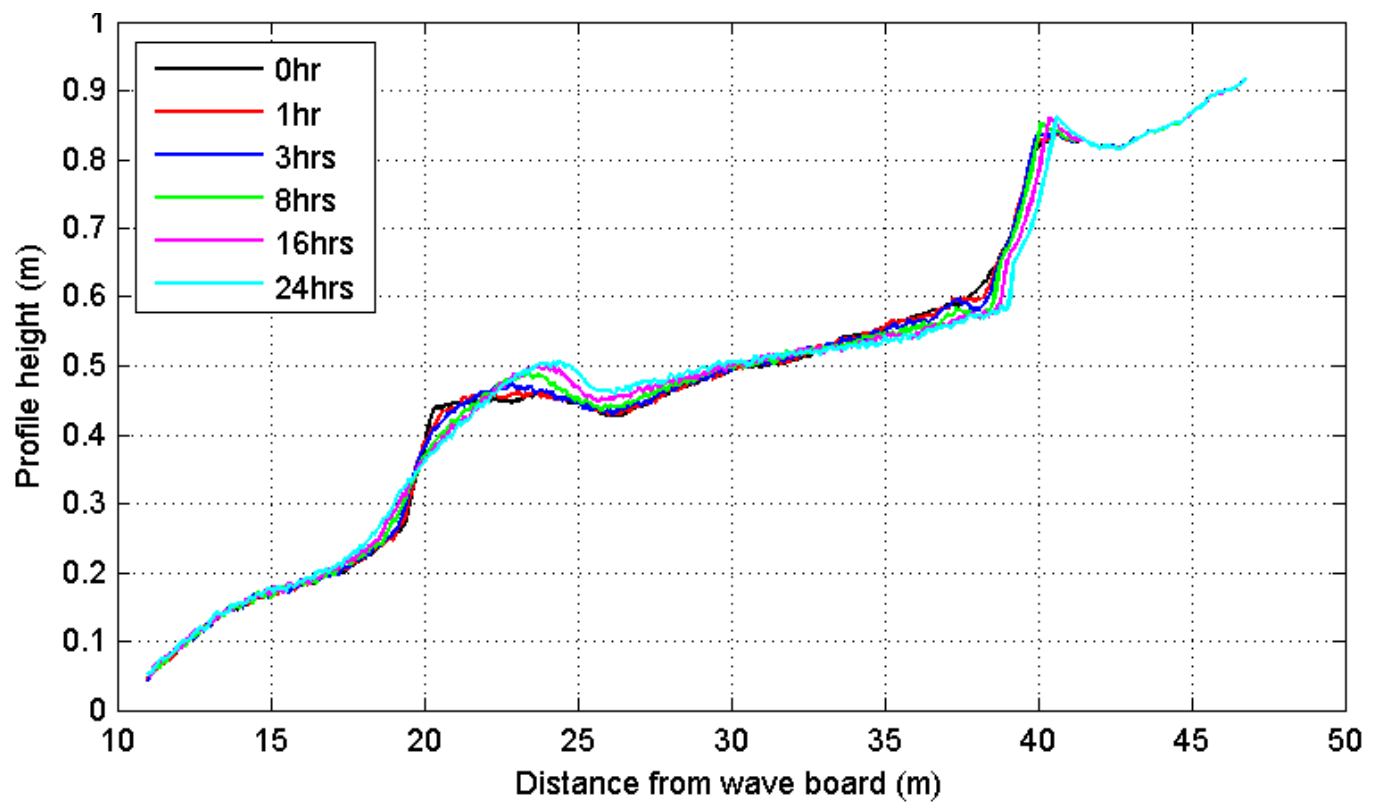

Figure 8. Observed profile development for the low nourishment profile under accretive wave conditions.

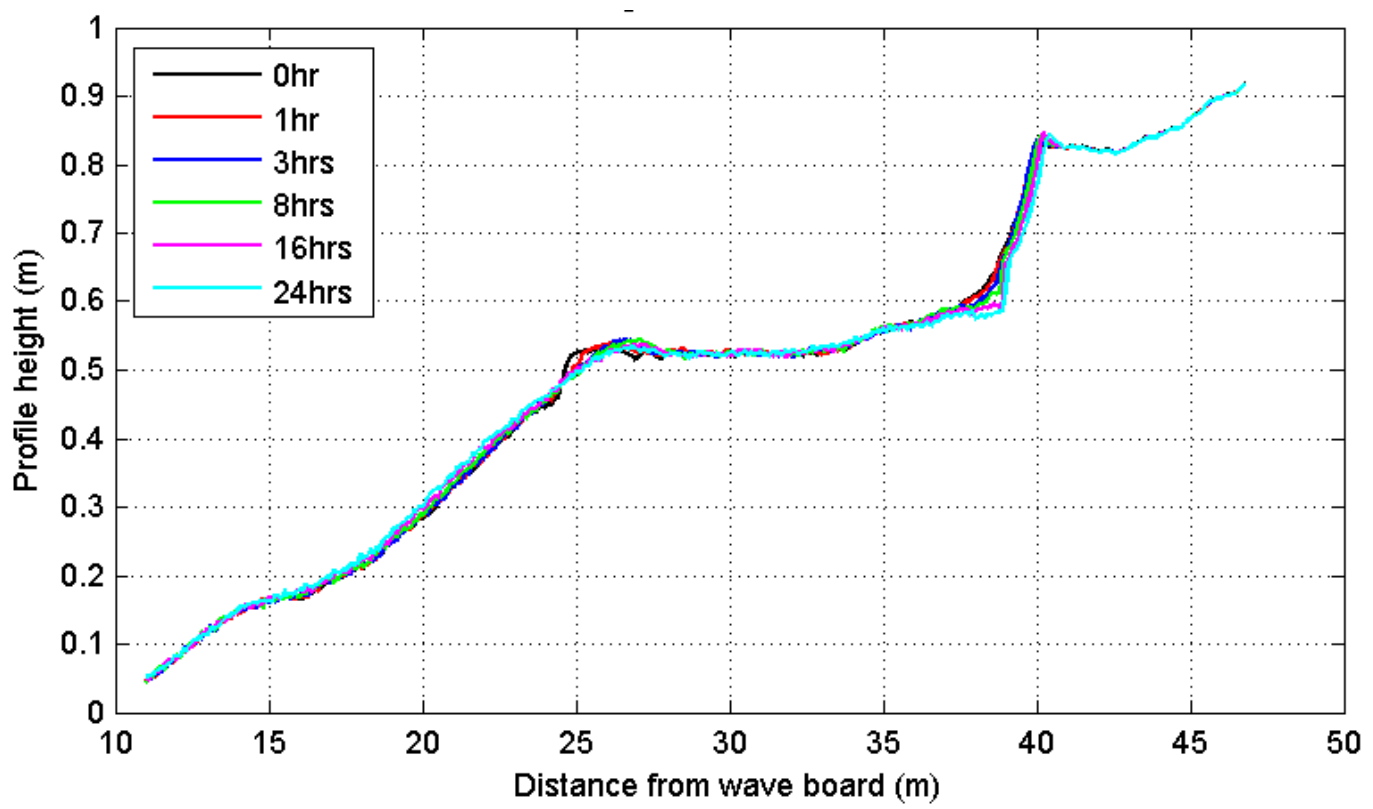

Figure 9. Observed profile development for the high nourishment profile under accretive wave conditions. 


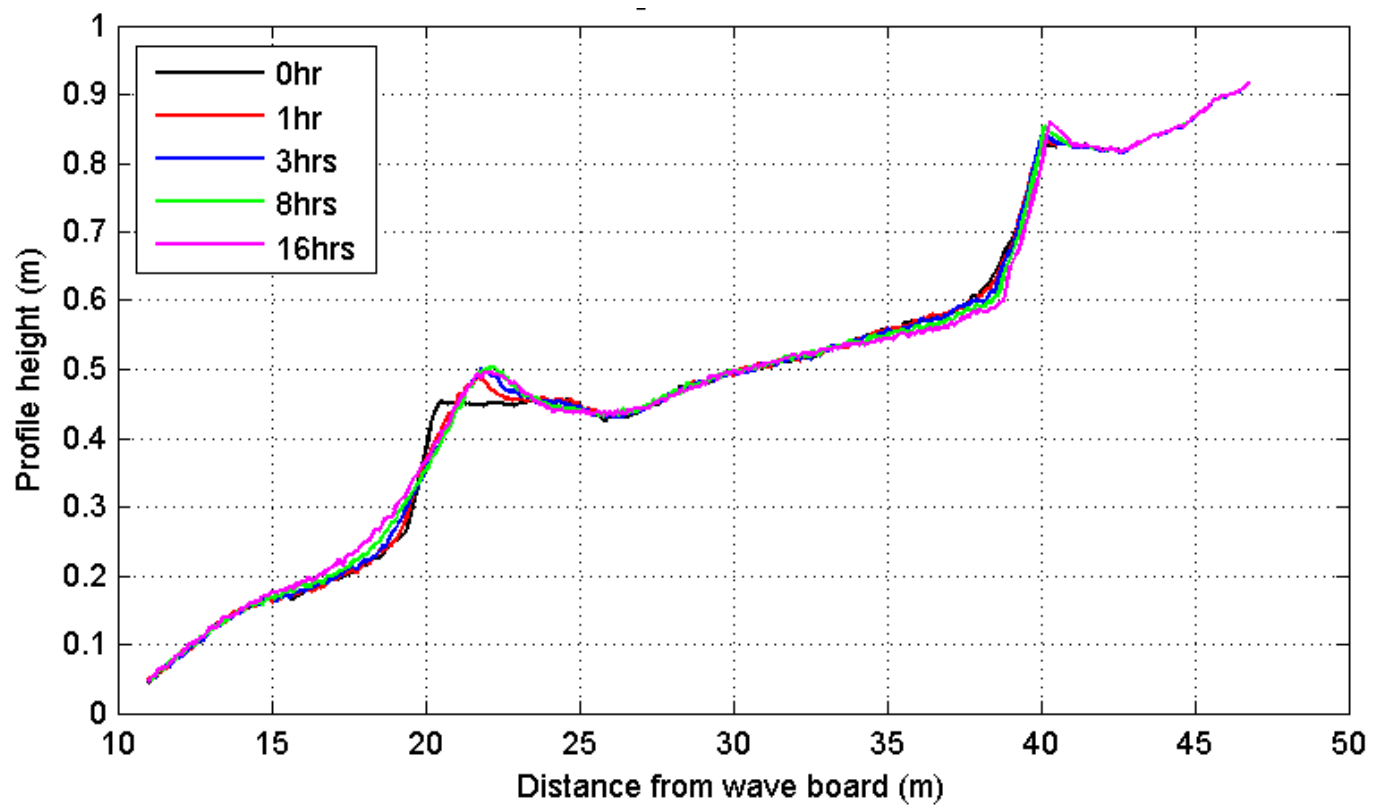

Figure 10. Observed profile development for the low nourishment profile under erosive wave conditions.

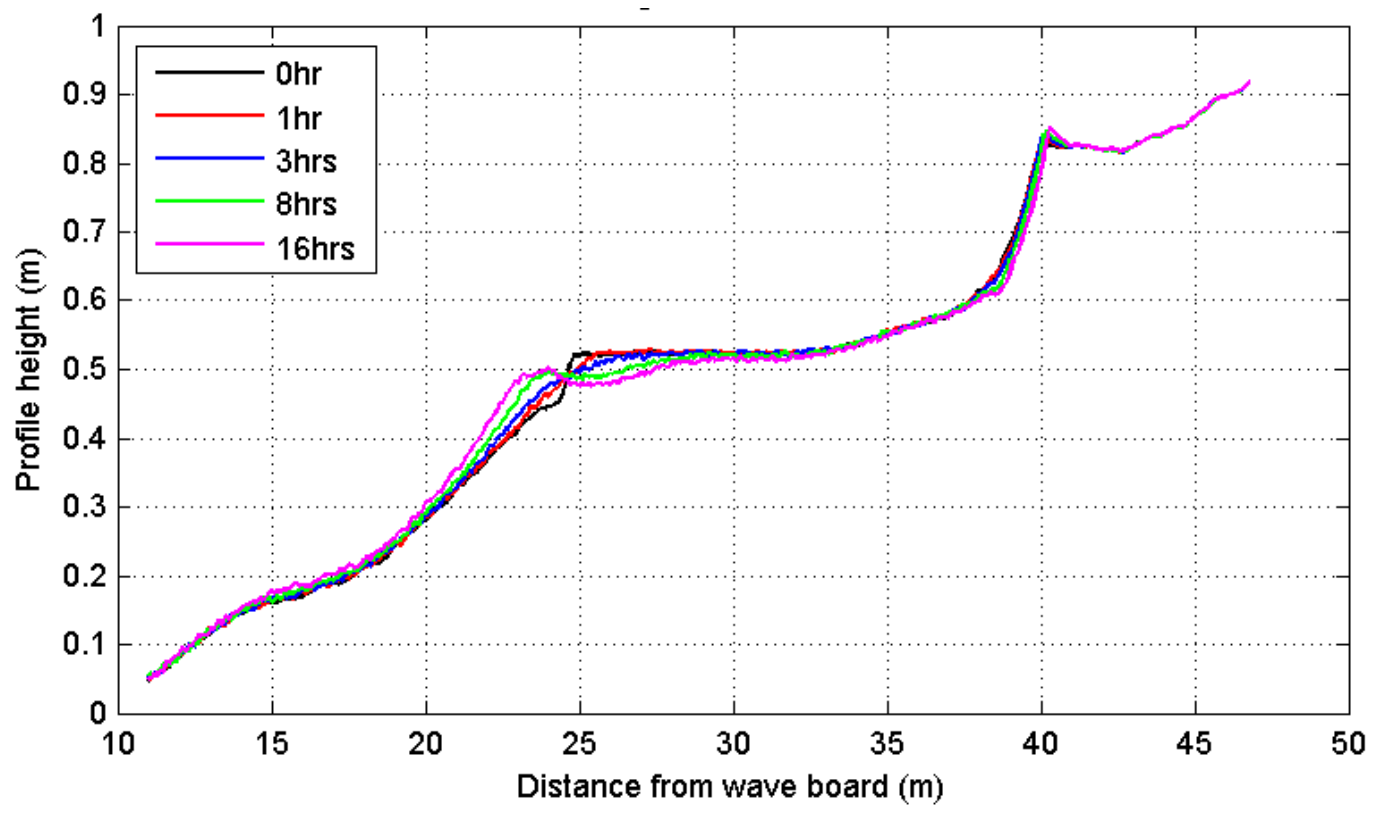

Figure 11. Observed profile development for the high nourishment profile under erosive wave conditions. 

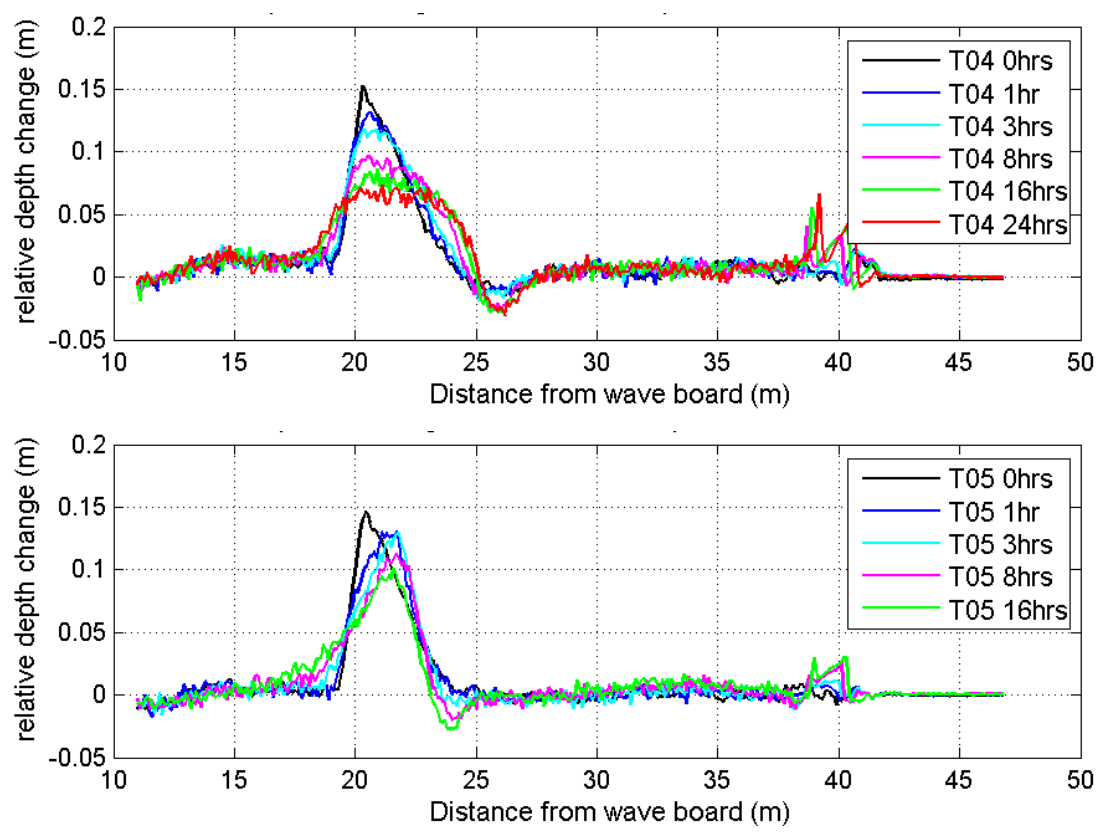

Figure 12. Profile change relative to reference case for the low nourishment design (top: accretive conditions, bottom erosive conditions).
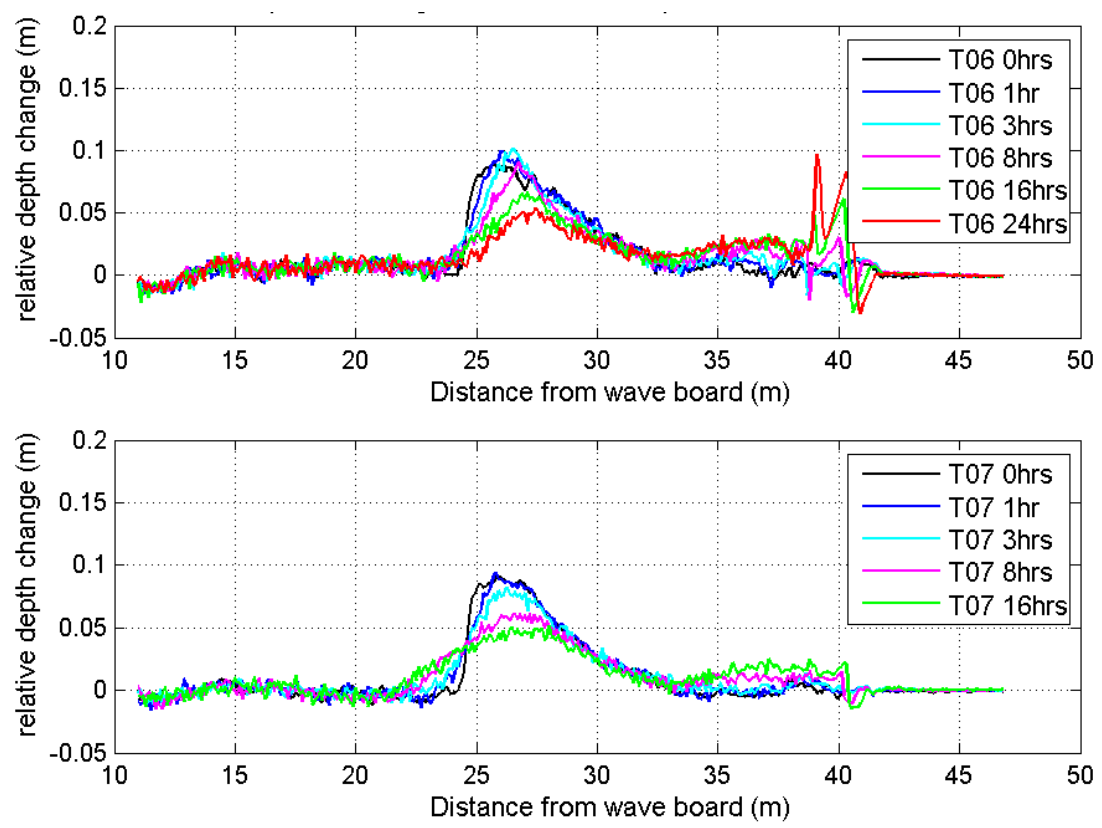

Figure 13. Profile change relative to reference case for the high nourishment design (top: accretive conditions, bottom erosive conditions). 

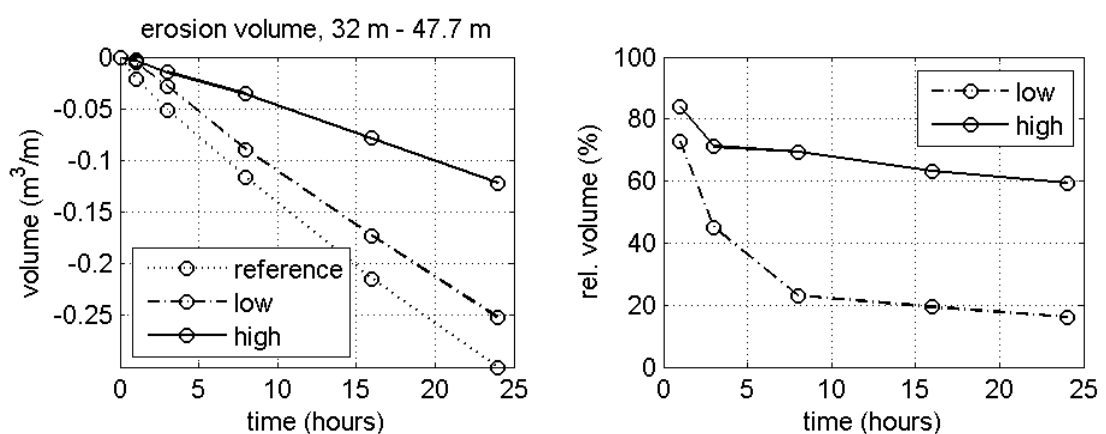

Figure 14. Left: absolute erosion volumes for the accretive tests for the reference profile (T02), the low nourishment design (T04) and high nourishment design from $x=32 \mathrm{~m}-47.7 \mathrm{~m}$. Right: temporal development of same volume, relative to the reference profile.
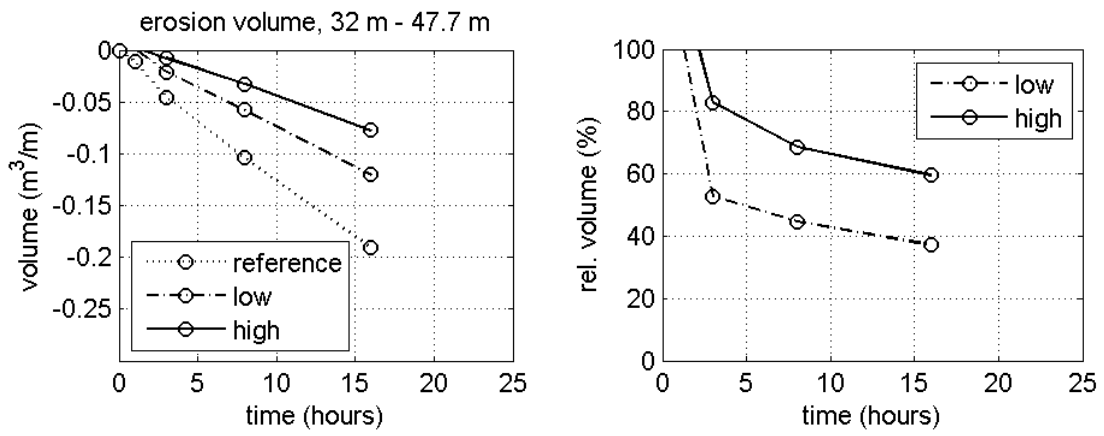

Figure 15. Left: absolute erosion volumes for the erosive tests for the reference profile, the low nourishment design and high nourishment design from $x=32 \mathrm{~m}-47.7 \mathrm{~m}$. Right: temporal development of same volume, relative to the reference profile.

\section{IDENTIFICATION OF DOMINANT PHYSICAL PROCESSES}

For the initial and final profile the observed cross-shore wave height distribution is shown in Figure 16 for all nourishment designs and both accretive and erosive wave conditions. Both nourishment designs have a major impact on the local wave height at the nourishments. For the upper part of the profile the low nourishment has no sheltering effect as can be seen from the fourth row of plots. The high nourishment results in a wave height decrease across the entire profile for both the accretive and erosive wave conditions.

The associate depth averaged wave induced return flow is compared in Figure 17. Enhanced velocities are present at the nourishments due to wave breaking. Near shore the effect of the nourishment is negligible for the accretive wave conditions, but for the erosive wave conditions the depth-averaged velocities have reduced noticeably for both nourishment designs.

Third order velocity moments, shown in Figure 18, are an indicator for the transport due to wave skewness. For the erosive condition, on top of the high nourishment, the third-order velocity moments are significantly larger than the other two tests. The third order velocity moments close to the coastline are more or less the same. However, as the wave heights are lower in the upper part of the profile, similar velocity moments imply increased wave skewness. 

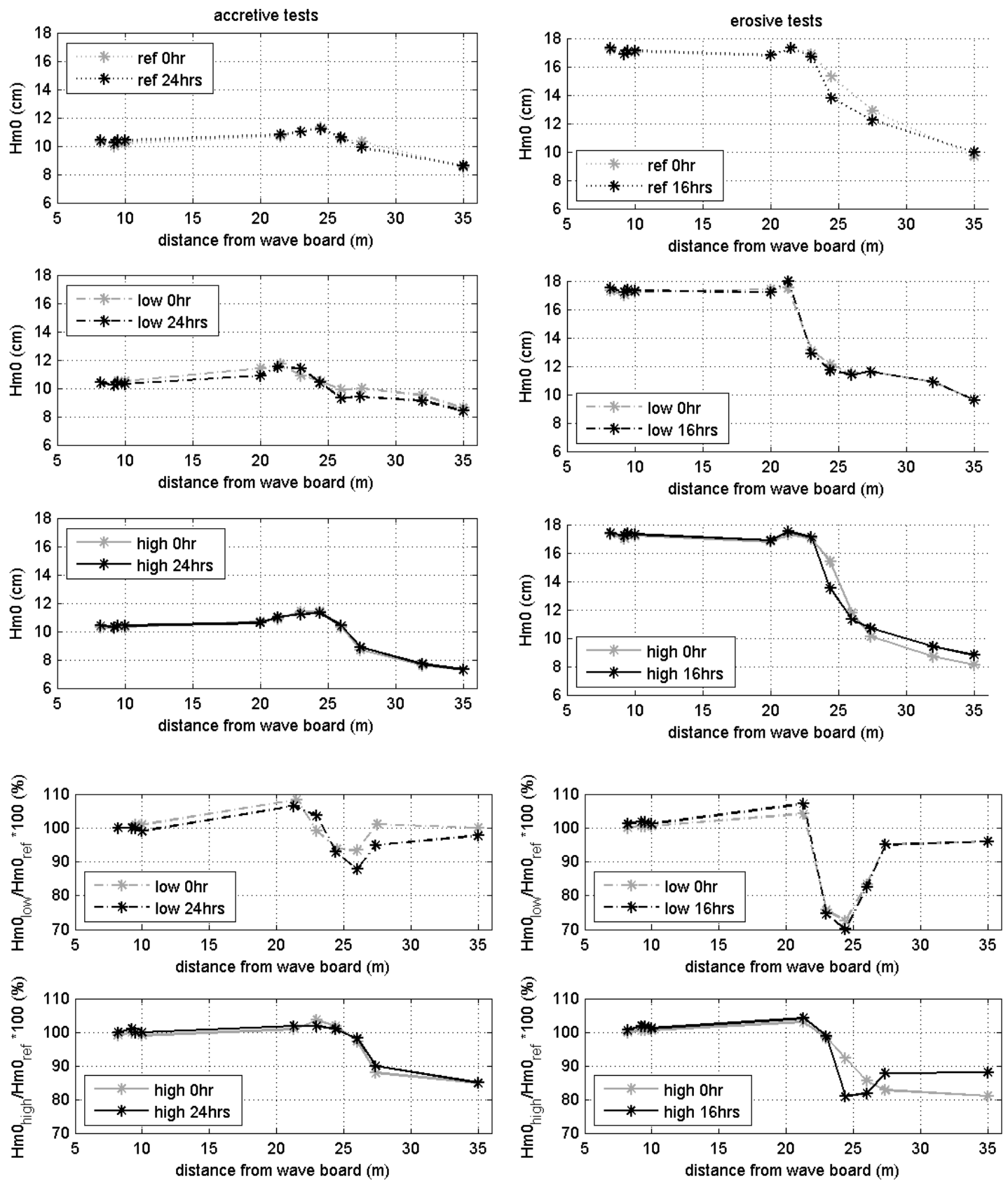

Figure 16. Cross-shore Wave height distribution for the accretive (left) en erosive conditions (right). Top row: reference profile, $2^{\text {nd }}$ row: low nourishment design, $3^{\text {rd }}$ row: high nourishment design, $4^{\text {th }}$ row: ratio of wave height for low nourishment and reference profile and bottom row: ratio of wave height for high nourishment and reference profile. 

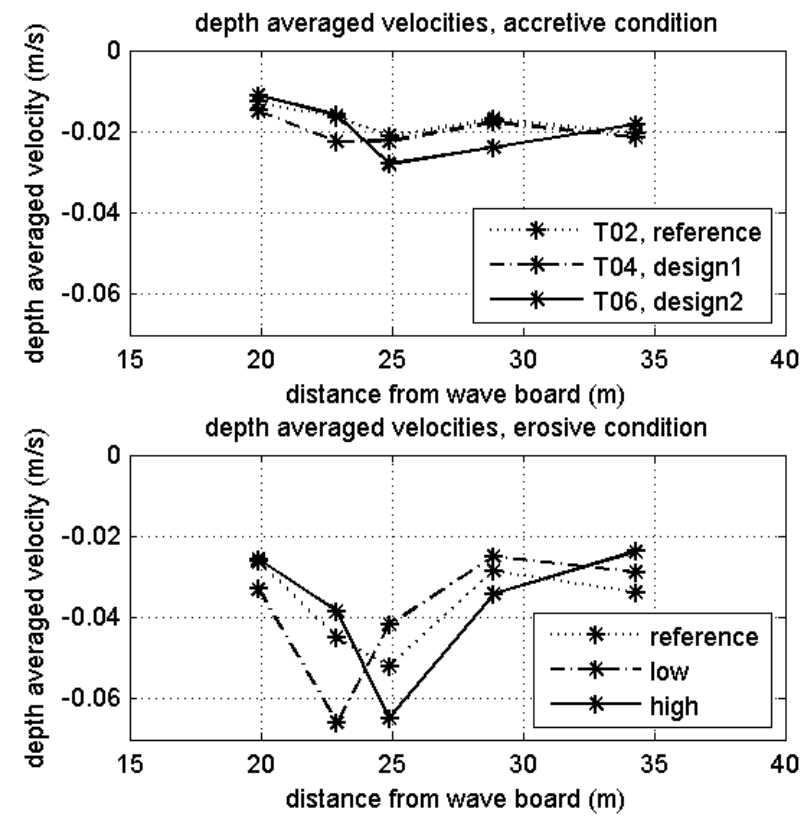

Figure 17. Depth-averaged velocities for the accretive (top) and erosive (bottom) wave conditions.
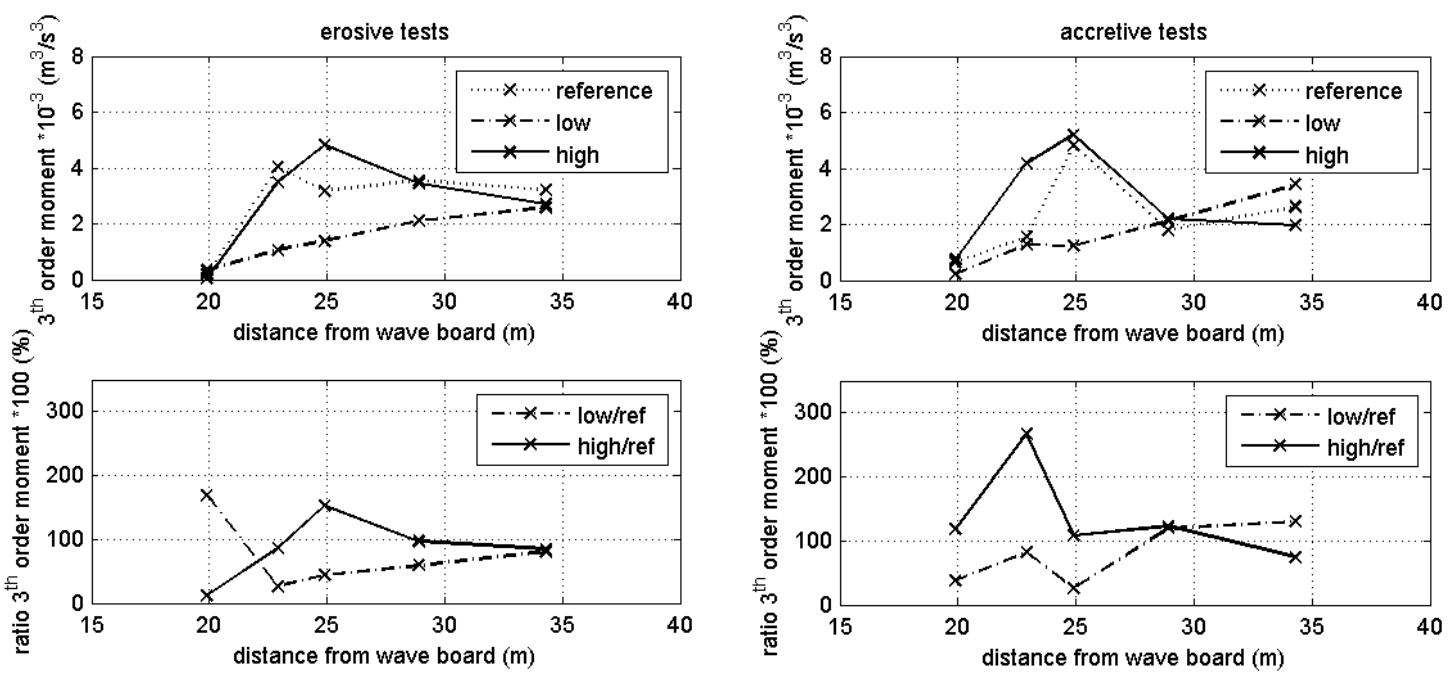

Figure 18. $3^{\text {rd }}$ Order velocity moments for the erosive conditions (left) and accretive conditions (right). Top row: absolute values, bottom row: ratio of the velocity moments of the nourishment designs and the reference profile.

\section{CONCLUSIONS}

Analysis of the data indicates that shoreface nourishments significantly affect the wave height, the wave-induced return flow, the wave skewness and the sediment transport, even when it is located in somewhat deeper water. The process measurements clearly show that the shoreface nourishments reduce the near shore wave climate. As a result the wave induced return flow is reduced which primary effect is a reduction of the offshore directed suspended transports. The reduced waves have become more skewed mainly resulting in a relative larger onshore bed load transport. This combined effect is a reduced offshore transport with the presence of the nourishments. 
Analysis of the samples of the bed sediments taken at different positions along the flume showed that on top of the breaker bar of the profiles of the reference tests and tests with the low nourishment, a slightly more coarse grain size is present compared to the grain size adjacent to the breaker bar. The nourishment in relative deep water reduces the erosion of the upper part of the profile by about $20 \%$ for the accretive condition and $40 \%$ for the erosive condition. The nourishment higher in the profile results in a reduction of the erosion volume of $60 \%$ for both wave conditions.

In the conducted experiments the shoreface nourishments act as a submerged breakwater. Due to the limited duration of the experiments, no interaction between the shoreface nourishment designs and the upper part of the profile could be observed. However, the onshore (offshore) migration of the breaker bar and the nourishments under accretive (erosive) conditions imply that experiments with a longer duration could result in an interaction between shoreface nourishments and upper part of the profile. In reality longshore effects (e.g. interruption of the longshore sediment transport) will also be important which could not be addressed in the present study.

\section{REFERENCES}

Bosman, J.J, E.T.J.M. van der Velden, C.H. Hulsbergen, 1987, Sediment concentration measurement by transverse suction. Coastal Engineering, 11: 353-370.

Hamm, L., Capobianco, M., Dette, H. H., Lechuga, A., Spanhoff, R. \& Stive, M. J. F., 2002. A summary of European experience with shore nourishment. Coastal Engineering, 47 (2), 237-264.

Koomans, R.L. and J. Bosboom (2000). Laboratory experiments on sediment dynamics and density gradation: Part I, time-averaged measurements. Delft Hydraulics report H2305.73.

Koningsveld, M. van, and J. Lescinski, 2006. Decadal scale performance of coastal maintenance in the Netherlands. Shore and Beach, 75(1), 1-17.

Van Duin, M.J.P., N.R. Wiersma, D.J.R. Walstra, L.C. van Rijn and M.J.F. Stive, 2004. Nourishing the shoreface: observations and hindcasting of the Egmond case, The Netherlands. Coastal Engineering, $51(8-9), 813-837$

Walstra, D.J.R., van Ormondt, M. and Roelvink, J.A., 2004. Shoreface nourishment scenarios : detailed morphodynamic simulations with Delft3D for various shoreface nourishment designs. Delft Hydraulics report Z3748.21. 